\title{
Aprendizagem cultural e mimese: jogos, rituais e gestos
}

\author{
CHRISTOPH WULF \\ Freie Universität Berlin, Berlim, Alemanha \\ Tradução e revisão técnica de \\ Carlos Eduardo Galvão Braga e Maria da Conceição Passeggi
}

RESUMO

Estudos recentes sobre primatas mostram que o homem é, de longe, o mais habilitado para aprender por mimetismo. Aristóteles já considerava que a aptidão para a aprendizagem cultural e o prazer de a isso se dedicar constituíam um dom próprio da espécie humana. Essas aptidões miméticas permitem à criança, na primeira infância, participar da produção e dos processos culturais da sociedade. $\mathrm{Na}$ primeira infância, a criança assimila as produções materiais e simbólicas de sua comunidade cultural, as quais, conservadas dessa maneira, são transmitidas à geração seguinte. Em ampla medida, a aprendizagem cultural é aprendizagem mimética, essencial em inúmeros processos de formação e de autoformação. Ela se estende ao outro, à comunidade social e aos bens culturais, cuja vitalidade é garantida por ela. A aprendizagem mimética, fundamentada no corpo e nos sentidos, permite a aprendizagem de imagens, de esquemas, de movimentos pertencentes à esfera da ação prática; ela se realiza, em grande parte, de maneira inconsciente, fato que induz efeitos duradouros em todos os campos da evolução cultural.

PALAVRAS-CHAVE

mimese; aprendizagem cultural; ritual; gesto; saber prático. 


\title{
CULTURAL LEARNING AND MIMESIS: GAMES, RITUALS AND GESTURES
}

\begin{abstract}
Recent studies with primates have shown that human beings are far more prepared to learn through mimicry. Aristotle considered that cultural learning capacity together with the pleasure of mimicry were typical abilities of human kind. Such imitative abilities allow young children to participate in social cultural processes and production. During childhood, kids assimilate material and symbolic productions of their cultural communities, which will be passed on to following generation in the same way. Much of cultural learning is ensured by mimicry, which is essential in countless training and self-training processes. It also reaches the social community and cultural assets, ensuring their vitality. Imitation learning, based on body and senses, fosters the learning of images, schemes and movements from the practice domain, and it happens largely unconsciously, leading to long-lasting effects in all fields of cultural evolution.
\end{abstract}

KEYWORDS

mimicry; cultural learning; ritual; gesture; practical knowledge.

\section{EL APRENDIZAJE CULTURAL Y LA MIMESIS: JUEGOS, RITUALES Y GESTOS}

\section{RESUMEN}

Estudios recientes sobre primates demuestran que el hombre es, por lo lejos, el más apto a aprender por mimetismo. Aristóteles ya consideraba que la capacidad de aprendizaje cultural y el placer de dedicarse a ella constituían un don propio de la especie humana. Esas aptitudes miméticas permiten que el niño participe, en la primera infancia, en la producción y los procesos culturales de la sociedad. En esa fase, el niño asimila las producciones materiales y simbólicas de su comunidad cultural, que conservadas de esa manera, se transmiten a la generación siguiente. En gran medida, el aprendizaje cultural es el aprendizaje mimético, que resulta esencial en innúmeros procesos de formación y de autoformación; se extiende al otro, a la comunidad social y a los bienes culturales, cuya vitalidad asegura. El aprendizaje mimético, fundada en el cuerpo y los sentidos, permite que se aprendan imágenes, esquemas y movimientos del dominio de la acción práctica; se realiza en forma mayormente inconsciente, lo cual induce efectos duraderos en todos los campos de la evolución cultural.

PALABRAS CLAVE

mimesis; aprendizaje cultural; ritual; gesto; saber práctico. 
Estudos recentes sobre os primatas mostraram que, se existem entre eles formas elementares de aprendizagem mimética, é o homem, de longe, o mais habilitado para aprender por mimetismo (Tomasello, 1999, 2008). Esse resultado não surpreendeu os pesquisadores. Aristóteles já considerava que a aptidão para a aprendizagem cultural e o prazer de a ela se dedicar constituíam um dom próprio da espécie humana. Com base nas pesquisas sobre o comportamento social dos primatas e comparando os resultados obtidos até então, especialistas em psicologia do desenvolvimento e em psicologia cognitiva chegaram a conclusões que se resumem em dois pontos essenciais: a presença, em uma idade precoce, de certo número de características do aprendizado mimético no ser humano e a afirmação do caráter específico do aprendizado mimético no homem. Ouçamos Michael Tomasello (1999, p. 161):

O lactente (ou a criança na primeira infância) identifica-se com o outro, percebe-o como ator intencional e faz o mesmo em relação a si; participa, com outros, das atividades que requerem uma atenção simultânea; apreende inúmeras relações causais entre os objetos físicos e os acontecimentos do mundo; reconhece as intenções de comunicação expressas pelos gestos, pelos símbolos linguageiros e pelas construções verbais. Imitando o outro ou trocando os papéis, ele aprende a produzir os mesmos gestos, os mesmos símbolos e construções, e a formar categorias de objetos baseados na linguagem e esquemas de acontecimentos.

Tais aptidões permitem à criança na primeira infância participar dos processos culturais. Assim, ela pode tomar parte nas encenações das práticas e dos savoir-faire do grupo social dentro do qual vive e apropriar-se de um saber cultural. As aptidões descritas enfatizam a importância, central no desenvolvimento da criança na primeira infância, dos modelos na aprendizagem. No entanto, compreendem-se melhor esses processos ao fazer intervir a ideia de mimetismo (Gebauer; Wulf, 1995, 2004a, 2004b). Identificar-se com o outro, compreendê-lo enquanto pessoa que age intencionalmente e fixar, ao mesmo tempo, a atenção nele são aptidões que participam do desejo mimético da criança de se igualar ao adulto e de se parecer com ele, ou seja, de vir a ser como ele. É no desejo de se parecer com os mais velhos que se deve buscar o que impele as crianças na primeira infância a compreenderem as relações causais entre os objetos do mundo. $\mathrm{O}$ mesmo se dá com a compreensão das intenções de comunicação do outro, sejam elas expressas por gestos, símbolos ou construções linguageiras. A criança na primeira infância pode, a exemplo dos adultos, formular categorias de objetos e esquemas de acontecimentos. Com 9 meses, ela dispõe de capacidades miméticas que outros primatas jamais desenvolverão ao longo da vida.

Essas aptidões miméticas permitem à criança na primeira infância participar da produção e dos processos culturais da sociedade. Elas favorecem aquilo que na psicologia chama-se de "aprendizagem por imitação" (ou "efeito catraca" - "effet cliquet"): a criança assimila as produções materiais e simbólicas de sua comunidade cultural, que, conservadas dessa maneira, são transmitidas à geração seguinte. 
Em um primeiro momento, os processos miméticos são dirigidos principalmente para os seres humanos. É assim que o lactente (e a criança na primeira infância) se refere às pessoas com as quais vive: pais, irmãos e irmãs mais velhos, amigos da família (Wulf, 2007, 2002, 1999). A criança procura se parecer com eles, responde a um sorriso com outro sorriso. Usando as capacidades adquiridas, ela já sabe despertar reações semelhantes no adulto. Nesses processos de troca precoces, a criança aprende os sentimentos; aprende a fazer nascer, nela mesma, sentimentos relativos ao outro e a provocá-los no outro. Seu cérebro desenvolve-se durante essas trocas com o mundo; certas possibilidades aumentam, outras permanecem inexploradas. As condições culturais dessa vida precoce inscrevem-se ao mesmo tempo em seu cérebro e em seu corpo. A criança que não aprende a ver, a ouvir e a falar na mais tenra idade não poderá adquirir essas aptidões posteriormente. Em um primeiro momento, as relações miméticas do lactente ou da criança na primeira infância não nos autorizam a pressupor a consciência de uma separação entre sujeito e objeto, que aparece em um estágio mais avançado do desenvolvimento. Sua percepção do mundo é mágica: os objetos são animados como os seres vivos. É com a aptidão para experimentar o mundo em suas correspondências - aptidão que perde sua importância com o desenvolvimento da racionalidade - que se formam as principais capacidades de transformação do mundo em imagens e de sua assimilação a um mundo interior de imagens (Wulf, 2013).

$\mathrm{Na}$ narrativa autobiográfica Infância berlinense, Walter Benjamin (2006) mostra de que maneira a criança assimila seu ambiente cultural pelos procedimentos da imitação. A criança explora certos compartimentos, recantos, objetos, certas atmosferas da casa de seus pais. As imagens dessas coisas tomadas como "marcas" vêm povoar seu mundo imaginário; elas se transformam em imagens e em lembranças novas que a fazem descobrir novos universos culturais. A transmissão da cultura se dá nesses processos de encarnação e descoberta das produções culturais. A aptidão mimética permite converter o mundo material em imagens e transferi-lo para um mundo de imagens interior, colocando-o, assim, à disposição de todos. Ela torna cada indivíduo capaz de organizar ativamente aquilo que a cultura the deu (Huppauf; Wulf, 2009).

Esses processos não se aplicam apenas à nossa relação com os produtos culturais materiais; eles também dizem respeito às relações sociais, às formas de ação, às encenações e representações do social. Aprendemos por mimetismo formas de saber prático, ao longo de processos que implicam o corpo e os sentidos. Esse saber prático permite agir com competência dentro das organizações e das instituições. O saber ritual constitui parcela significativa desse saber social prático, que insere as instituições nos corpos e os habilita a orientar-se em um contexto social. Nos processos miméticos, o indivíduo adquire as imagens, os esquemas e os movimentos que lhe darão a capacidade de agir. Na medida em que são orientados para produções históricas e culturais, cenas, arranjos, representações, os processos miméticos estão entre os mecanismos mais importantes que garantem a passagem da cultura para a geração seguinte. Sem a aptidão para o mimetismo, não existiriam nem aprendizagem cultural, nem "dupla hereditariedade", ou seja, a transmissão de bens culturais que, no caso do homem, caminha com a hereditariedade biológica e permite, ao mesmo tempo, o desenvolvimento e a transformação da cultura. 
A escrita, como conjunto de semelhanças não sensíveis, envolve processos miméticos por meio dos quais aquilo que se lê pode ganhar vida. $\mathrm{O}$ mesmo acontece com outros bens culturais que só se animam na relação mimética. Sem a escrita, eles representam apenas um potencial mimético; seu sentido só se manifesta ao longo da formação e da autoformação. Esses processos mostram-se particularmente importantes por ocasião das transferências culturais de uma geração para a seguinte. Com efeito, eles implicam metamorfoses necessárias à preservação de formas de vida, de saber, de arte e de técnica. Os processos miméticos não geram simplesmente métodos de cópia de mundos já simbolicamente interpretados. Poder-se-ia dizer que o ser humano recolhe as "marcas" desses mundos e as assimila. Pelo fato de transformarem o mundo dado originalmente, as relações miméticas comportam sempre um aspecto criador. Decorre daí uma dinâmica cultural entre as gerações e as culturas, que constantemente produz algo de novo.

Em ampla medida, a aprendizagem cultural é aprendizagem mimética, essencial em inúmeros processos de formação e de autoformação. Ela se estende ao outro, à comunidade social e aos bens culturais, cuja vitalidade é garantida por tal aprendizagem. A aprendizagem mimética, fundamentada no corpo e nos sentidos, permite a aprendizagem das imagens, dos esquemas, dos movimentos que dizem respeito à ação prática. Ela ocorre de maneira amplamente inconsciente, o que induz efeitos duradouros em todos os campos da evolução cultural.

Os processos miméticos estão vinculados aos processos de contágio com a experiência da dissolução da subjetividade em situações caóticas e nos surtos de violência (Girard, 1977, 1986), podendo acarretar conflitos de poder, de dominação, de violência e opressão, que são parte integrante de qualquer cultura e fazem intervir constantemente o mimetismo. $\mathrm{O}$ círculo vicioso da violência é um bom exemplo da estrutura mimética de muitos fenômenos de violência. No entanto, os processos decorrem também de aspirações e de experiências intensas, semelhantes às "experiências vivas" de que falava Adorno. Imitar o mundo oferece ao humano a possibilidade de se desfazer do egocentrismo, do logocentrismo e do etnocentrismo, além da possibilidade de abrir-se às experiências do outro.

\section{HISTÓRIA E CULTURA}

Um breve exame da história do conceito é suficiente para demonstrar que os processos culturais participam do mimetismo. Se, como escreveu Platão, a mimese é sinônimo de educação; se processos miméticos produzem a arte e a poesia; se obras poéticas e artísticas são transformadas em experiência estética, trata-se então da transmissão, da produção e da comunicação de obras culturais. Segundo Hermann Koller (1954), a representação e o conceito de processo mimético têm sua origem na dança e, portanto, expressam o aspecto performativo da cultura grega. Partindo dessa hipótese, Koller destaca os aspectos originais seguintes: a "representação", a "expressão" e a "imitação". O conceito ganha importância ao ser empregado por Platão na obra $A$ República. Ao passo que, no terceiro livro, Platão (1968) dá ao termo caráter geral, no livro X ele o restringe à esfera da arte e, ao fazê-lo, o desvaloriza. 
Ao contrário de Koller, pensamos hoje que o termo "mimese" chegou à Grécia por meio da Sicília, o país dos mímicos. A diferenciação possível do conceito com base nas análises linguísticas leva-nos a duas pistas (Else, 1958; Soerbom, 1966). A mimese não se relaciona de modo particular com a música e a dança, mas com mimos, a mímica. A atividade do mímico não é imitar ou produzir um efeito de semelhança, mas representar uma farsa, comportar-se à maneira de um mímico. Essa atividade remete à cultura cotidiana das pessoas simples, que era representada nos palcos, por ocasião das festas dadas pelos ricos, com a intenção de diverti-los. Em semelhante contexto, as encenações e as representações eram muitas vezes grosseiras e desrespeitosas. De acordo com essa concepção abonada por testemunhos escritos, os primórdios do conceito de mimese encontram-se em práticas culturais performativas que têm um caráter físico acentuado e ressaltam os movimentos do corpo. No século V a. C., esse conceito estava amplamente difundido na Jônia e na Ática. Ele já era utilizado, na época platônica, para designar processos "de imitação" (nachabmen), "de emulação" (nachstreben) e de competição (nacheifern).

Ao refletir sobre o fato de que os poetas desempenham, na Grécia, um papel importante na educação das novas gerações, Platão (1968), no terceiro livro de $A$ República, analisa o modo pelo qual as obras literárias podem exercer suas virtudes educativas por meio dos processos miméticos. As figuras e as ações nascidas da poesia, diz ele, inscrevem-se no imaginário dos jovens no decorrer de processos miméticos. Essas imagens são de tal força que os jovens não conseguem resistir a elas. É por isso que é importante escolher cuidadosamente as narrativas e as imagens que se vão sedimentar na imaginação deles. Mas a jovem geração também deve ser protegida de outros conteúdos. Por isso, convém efetuar, na pólis, uma seleção das narrativas poéticas que seja favorável aos objetivos da educação. É pela mediação da cidade que se exerce um controle sobre os processos miméticos destinados a formar o imaginário da juventude. É preciso banir aquilo que não serve aos fins educativos, a exemplo dos textos literários que tratam das fraquezas dos deuses e dos heróis. Só serão propostos aos jovens conteúdos literários que lhes permitam, pela mediação mimética, aprender aquilo que eles precisam saber para realizar suas tarefas dentro da pólis.

Segundo Platão, pintores e poetas não fabricam objetos usuais à maneira dos artesãos; eles recriam a aparência das coisas. A pintura e a poesia não consistem na representação artística das coisas, mas na representação artística das coisas tais como elas aparecem. O objetivo da arte não é a representação da realidade ou da verdade, mas a representação artística dos fenômenos tais como eles aparecem. É por isso que a pintura e a poesia miméticas podem, em princípio, fazer aparecer tudo aquilo que é visível (Huppauf; Wulf, 2009). Mas, nesse caso, trata-se da mimese que cria imagens e ilusões, em que a diferença entre o modelo e sua representação revela-se desimportante. $\mathrm{O}$ que se pretende alcançar não é a verdadeira representação ou a semelhança, mas a aparência daquilo que aparece. A arte e a estética constituem-se como um domínio próprio no qual o artista, ou o poeta, é soberano. É certo que ele não tem, segundo Platão, a capacidade de produzir o ente, mas não está, como o filósofo, submetido à obrigação da verdade. Platão atribui ao domínio estético certa independência em relação aos interesses da filosofia, sua busca de verdade e 
de conhecimento, seus esforços para alcançar o bem e o belo. O preço pago pelo artista é sua exclusão da cidade ideal, que, no caso da arte e da poesia, rejeita um caráter não subordinado aos seus objetivos.

Também para Aristóteles, a arte é mimese. A música, sobretudo, é imitação da moral. Diferentemente da pintura e da escultura, que formam linhas visíveis, a música cria um movimento interior sensível e provoca efeitos éticos. No centro da poética encontra-se a tragédia enquanto mimese de seres humanos atuantes. $\mathrm{Na}$ tragédia, não se representa nada que já não tenha acontecido. Com efeito, os temas e as concepções da ação enraízam-se no mito; qualquer enunciado referente à realidade seria absurdo. A ação da tragédia deve ser representada de tal modo que o espectador sinta, em um processo mimético, "terror"e "piedade", que ele atravesse uma experiência catártica e saia dela fortalecido (Ricœur, 1984-1988).

De acordo com Aristóteles (1958), as ações miméticas não criam uma cópia da realidade, na qual desapareceria a diferença entre o modelo e sua imitação. Os processos miméticos podem conduzir à imitação e à mudança; o que eles pretendem é "embelezar" e "melhorar", "imitar dando forma". A representação de Aquiles por Homero é um bom exemplo disso. Por mais que Aquiles seja descrito com os traços de um homem colérico e negligente, sua entrada em cena é a de um herói superior. Na poesia, deve-se ao processo mimético a conformação do possível e do geral. Assim, um novo elemento intervém no processo de imitação, elemento que não se limita à simples reprodução.

Na poesia, na pintura e na música, as obras culturais nascem em um processo mimético, pela imitação da natureza. Para compreender tal fato, convém partir de uma definição clara da natureza. Ao contrário do conceito de natureza corrente nos séculos XIX e XX, que reduz a natureza a um objeto, a physis designa, em Aristóteles, o poder, inerente à natureza, de dar vida: a natureza animada. Se a poesia, a pintura e a música devem imitar a natureza em um processo mimético, elas não se contentam em reproduzir ou representar de modo naturalista. Se considerarmos que a natureza é animada, que um princípio espiritual opera dentro dela, imitar a natureza ganha então outro significado. A poesia, a arte e a música devem imitar a força criadora da natureza. Nessa acepção, o caráter de imitação em sentido restrito perde sua importância. O que deve ter acesso à representação é algo cuja imagem é concebida pelo poeta ou pelo pintor. $\mathrm{O}$ resultado independe da semelhança com pessoas ou coisas que existem. Imitar não significa fabricar uma cópia, mas elaborar uma imagem que tem, decerto, um modelo, mas não o copia.

Os processos miméticos visam criar uma imagem interior que já se encontra diante dos olhos do pintor ou do poeta. No processo da criação artística, elabora-se algo novo. A ideia que norteia o processo criador dissolve-se cada vez mais na imagem, no drama ou no fragmento musical; com efeito, a obra ganha forma em certa mediação, e não mais somente na imaginação do artista. Ocorrem modificações, certos elementos são descartados, outros são acrescentados, e assim por diante, de modo que a semelhança já não é tão sensível. Frequentemente, os modelos aos quais se referem as imagens e os esboços dos pintores e dos poetas não são conhecidos, seja porque jamais existiram, seja porque não foram conservados. No centro do processo artístico encontra-se a imagem, que pode referir-se a um modelo ou ter 
sido transformada em obra de arte pelo simples processo artístico. Seja como for, a criação da imagem implica a transformação do modelo.

Que relação existe entre o modelo e a cópia? A cópia é criada pelo modelo? Como se deve compreender essa relação? Se considerarmos a célebre estátua de Zeus, esculpida por Fídias, cabe perguntar se existiu um modelo - e, se for o caso, onde. Ela nasceu no próprio processo artístico, no trabalho com o material. Quem vê a estátua reconhece a imagem, embora o modelo - "Zeus"-, que não existia antes dessa representação, seja desconhecido. Daí pode-se concluir que "a obra de arte é uma imagem à procura de um modelo", criada "para ir ao encontro, no espírito dos humanos, de um modelo - Vorbild: uma pré-imagem - e assim realizar sua missão, que é tornar-se imagem" (Zuckerkandl, 1958, p. 233). Essa imagem não é unívoca, não é uma resposta, mas antes uma pergunta que a obra de arte faz a quem olha para ela, e à qual o observador pode dar diversas respostas. Por meio de uma estrutura implícita à obra, criam-se imagens, configurações de sentido e de interpretações possíveis que fazem a complexidade e a materialidade da obra de arte.

Nessa perspectiva, a arte e a literatura nascem do encontro entre uma obra e um espectador. A relação de mimetismo muda de lugar. A obra de arte já não é concebida como imitação de um modelo. $O$ processo imitativo se dá entre a obra e o espectador. Enquanto momento do comportamento mimético, a experiência estética ganha uma importância fundamental. A obra de arte compreende, realmente, certos conteúdos e certas formas, sentidos possíveis, uma mensagem. No entanto, tudo isso só começa a viver na experiência estética. $\mathrm{O}$ conceito de mimese perde sua importância na estética da modernidade. A ideia da criatividade originária do homem entra em conflito com uma concepção da mimese reduzida à imitação, $\mathrm{o}$ que ocasiona o declínio do conceito.

Os processos miméticos têm um papel importante na formação e na educação, na criação e na transmissão da poesia, da arte e da música, bem como na aquisição de um saber social prático - este último aspecto será desenvolvido mais adiante neste texto. Mas esses processos atuam tanto na constituição quanto na própria destruição das sociedades. Eles penetram as hierarquias e a ordem social, manifestando nelas seus efeitos ambivalentes; contribuem para construir a ordem social, mas, ao mesmo tempo, colocam-na em perigo e concorrem para a sua destruição. Por um lado, deixam-se conter e canalizar; por outro, ameaçam - a exemplo de uma multidão que se vai formando - desencadear a violência e tornarem-se incontroláveis.

O reconhecimento do "caráter contagioso" dos processos miméticos serviu de ponto de partida para uma teoria importante sobre a origem da violência social. A apropriação mimética de atitudes e formas de agir acarreta sentimentos de concorrência e de rivalidade entre o imitador e aquele que é imitado, o que pode ser fonte de violências. Daí decorre uma situação contraditória: a apropriação, pelo imitador, das características do imitado é incompatível com o desejo respectivo das duas partes de se diferenciar e de afirmar, cada uma delas, seu caráter único. Essa situação paradoxal conduz a um aumento do potencial de violência social.

As ações carregadas de forte intensidade emotiva parecem particularmente aptas para suscitar processos miméticos; o caráter contagioso do riso é proverbial, assim como acontece com o amor e a violência. Segundo René Girard (1986), a 
violência respondia à violência nas culturas primitivas, gerando um círculo vicioso que reforça a dimensão e a intensidade da violência. Não raro, ela ameaça a coesão das sociedades que se esforçam, então recorrendo a interditos e rituais, para dominar uma violência incrementada pelo mimetismo.

Por ocasião das crises miméticas, nos momentos em que a violência explode e em que os interditos e os rituais já não bastam para represá-1a, ocorre que se proceda ao sacrifício ritual de um "bode expiatório", a fim de superar a crise (idem). Escolhe-se de comum acordo uma vítima potencial, que é designada como bode expiatório e sacrificada. $\mathrm{Na}$ união de uma comunidade coesa, desenvolve-se uma "mimese de adversário", isto é, uma aliança contra a vítima declarada como inimiga. Como regra geral, escolhe-se por unanimidade alguém que não sabe se defender e cuja morte não acarretará violências adicionais. O próprio sacrifício é um ato de violência, entretanto espera-se que ele ponha fim ao círculo mimético da violência. Por meio desse ato, a comunidade une-se solidariamente contra a vítima e parece livrar-se de uma violência que lhe é inerente.

\section{AGIR SOCIAL E APRENDIZAGEM MIMÉTICA NOS RITUAIS}

A capacidade de agir em sociedade é adquirida, por mimetismo, ao longo de diferentes processos culturais de aprendizagem. Foi o que mostraram muitos estudos recentes. De acordo com o traço cultural recebido, os seres humanos desenvolvem, nos processos miméticos, aptidões diversas para o jogo, para a troca de presentes, para os atos rituais. É preciso dispor de um saber prático para agir de modo conveniente em uma determinada situação. Esse saber é adquirido ao longo de processos miméticos de aprendizagem que envolvem, ao mesmo tempo, o corpo e os sentidos. É também em uma abordagem mimética que se pode apreender as características culturais do agir social. O saber prático e o agir social são indiscutivelmente modelados pelos fatores históricos e culturais.

Em uma primeira abordagem, serão qualificadas de miméticas as ações sociais que respondem aos requisitos seguintes:

a) referem-se, enquanto movimentos, a outros movimentos;

b) são compreendidas como representações ou encenações dos corpos;

c) trata-se de ações autônomas que são compreendidas por elas mesmas e que se podem referir a outras ações ou a outros mundos (Gebauer; Wulf, 2004a).

As ações que envolvem o cálculo, as estimativas, um comportamento reflexivo ou rotineiro não pertencem à esfera do mimetismo; os atos isolados ou as infrações à regra também não.

Com o exemplo de um ritual pertencente à cultura do cotidiano, proponho-me a ilustrar a relação entre agir social, saber prático e aquisição de um saber mimético. A aprendizagem cultural nos processos miméticos é, muitas vezes, baseada nos rituais e nas ritualizações (Wulf et al., 2004a, 2007). Poderia mostrar a mesma coisa com relação aos jogos e aos gestos (Wulf et al., 2004b, 2010, 2011); limitar-me-ei aqui aos rituais. 
De um ponto de vista diacrônico, mas também sincrônico, os processos miméticos desempenham um papel importante no bom êxito do agir ritual. Durante a representação dos rituais, os participantes referem-se simultânea e diretamente ao que fazem os outros participantes. As coisas ocorrem de maneira essencialmente mimética, por meio dos sentidos, dos movimentos do corpo, de uma relação comum com as palavras, os sons, a língua e a música. Uma ordenação ou um acontecimento total só pode existir se a coordenação e a regulação minuciosa de todas as ações rituais tiverem sido bem orquestradas. A encenação é a condição sine qua non. Mas o elemento decisivo é a representação, na qual todas as ações rituais devem ser coordenadas. Se faltar essa coordenação, produz-se um efeito cômico, e o ritual não dá certo. Em nome da harmonia, as ações devem estar em uma relação mimética umas com as outras. Se isso ocorrer, cria-se um fluxo de energias entre os participantes, e a experiência é sentida como intensa, agradável e criadora de união. Como acontece na dança ou na sedução, nos rituais o controle racional das ações tem seus limites. $\mathrm{O}$ sentimento de sucesso só intervém se, para além do controle racional, instaurar-se uma harmonia criada, por mimetismo, entre os corpos, os movimentos e os gestos. $\mathrm{O}$ evento mimético está na origem dos sentimentos de pertença e de comunidade e, ao mesmo tempo, na base da experiência do sagrado.

A dimensão sincrônica ressalta a importância dos processos miméticos na realização imediata dos rituais, ao passo que a dimensão diacrônica caracteriza seu aspecto histórico. Os rituais sempre fazem referência a rituais que já aconteceram, dos quais os protagonistas atuais já participaram ou ouviram falar. Por isso a dimensão histórica constitui uma condição prévia: uma ação ritual implica uma referência mimética a um ritual anterior. Uma vez que este último aconteceu por mimetismo, o que se evidencia é o "vestígio" de um ritual passado, adaptado ao contexto atual. De acordo com as exigências, pode ocorrer uma variação em relação às figurações rituais anteriores. Graças a essa relação mimética entre o mundo atual e um mundo passado, é estabelecida uma continuidade histórica que legitima o agir ritual, mesmo quando ele constitui um desvio em relação ao modelo. A referência mimética não significa que o ritual seja imitado com exatidão a cada vez. A referência mimética é a "assimilação", ou seja, a repetição de uma ação semelhante que não seria possível se a ação ritual anterior não tivesse acontecido. Em certos casos, ela acarreta um distanciamento crítico em relação à perspectiva escolhida para o ritual, sem, no entanto, torná-la supérflua.

$\mathrm{Na}$ referência mimética, figurações e ordenamentos rituais são atualizados e modificados em virtude das necessidades da ação. Os participantes apropriam-se das constelações miméticas, dos estilos de encenação e dos tipos de movimento, que eles modificam de acordo com o gosto ou a necessidade. Com a "repetição" de rituais mais antigos, não se executa apenas uma cópia, como a que poderia ser produzida em uma impressora. Pelo contrário, cria-se, para todos os participantes, algo novo a partir de elementos mimeticamente transferidos e assimilados; nesse "novo", há retomada (Aufhebung) de todos os elementos anteriores. Atualizado no processo mimético, o ritual inclui o antigo, com outros trajes e cara nova. 


\section{O EXEMPLO DE UM RITUAL PERTENCENTE À CULTURA DO NOSSO COTIDIANO E A APRENDIZAGEM DO SABER PRÁTICO NOS PROCESSOS MIMÉTICOS}

Eis um exemplo que pode ilustrar a relação entre o agir ritual, o saber prático e a aquisição do saber mimético:

Uma mulher comemora seu aniversário; seu companheiro quer lhe dar um presente e pensa no que poderia ser de seu agrado. Em um primeiro momento, ele não tem muitas ideias: não pode ser um objeto de uso corrente, que ela mesma poderia comprar. Ele também rejeita a ideia do conjunto para fondue que ela lhe mostrou em um catálogo: mais que um presente de aniversário para ela, seria um presente para o casal, e impessoal demais para a sua companheira. Seus pensamentos giram em torno do que poderia lhe agradar e dar prazer. Em uma livraria, ele procura algum título na seção de livros de arte e de lançamentos de romances. Então se lembra de que no ano anterior ela ofereceu a ele um livro com imagens dos primeiros tempos da fotografia. A ideia do livro não é, portanto, uma boa ideia de presente. Em um antiquário, ele se põe a procurar um candelabro ou uma luminária antiga. Gosta do que encontra, mas ainda não está plenamente satisfeito. É então que ele vê um anel ornamentado por um rubi-califórnia. $\mathrm{Na-}$ quele momento, lembra-se de que um dia ela lhe falou de um anel parecido com aquele, que era da avó dela e que, para sua alegria, ela teve, em diversas ocasiões, a permissão de usar. Agora ele tem certeza de que encontrou o que procurava.

Na manhã do aniversário da mulher, ele arruma velas e cascas de nozes em um recipiente de vidro cheio de água e de folhas de hera; ao lado, o bolo de aniversário, um grande buquê de rosas, uma garrafa de champanhe e, como surpresa, o anel, embrulhado para presente. $\mathrm{O}$ café da manhã é servido na mesa posta para a festa. A mulher espera, em outro compartimento, que ele acenda todas as velas e abra a garrafa de champanhe. Ele a abraça, e os dois trocam palavras de carinho. Toda a situação e o presente escolhido com tanto amor enchem a mulher de alegria. Os dois se sentam e tomam um café um pouco mais demorado que de costume; o dia começa.

Essa sequência narrativa nos diz de que modo um homem sai em busca de um presente de aniversário e, depois de algumas dificuldades, encontra a maneira de encenar e representar a oferenda e a pequena festa na manhã do aniversário. A empreitada, bem-sucedida, proporciona grande satisfação; seus esforços são recompensados, e isso lhe dá um imenso prazer. Enquanto procura o presente, o homem evita tomar decisões que teriam diminuído a importância da escolha aos olhos de sua mulher. Por isso, ele não escolhe nem um presente útil, nem um presente "genérico"; ele também evita um presente parecido com o que a mulher lhe havia dado recentemente. Depois de muito procurar, ele encontra um que é particularmente apropriado à sua companheira e que deveria agradar a ela mais do que a qualquer outra pessoa. A sensibilidade de que ele deu provas em sua escolha estende-se aos preparativos afetuosos da festa matinal, às velas que flutuam entre folhas de hera, 
às rosas, ao champanhe, ao bolo de aniversário, ao presente bem embalado, à mesa festiva, às palavras carinhosas e ao seu jeito de abraçá-la.

De que maneira esse homem que comemora o aniversário de sua mulher sabe o que deve fazer para demonstrar seu amor e fazer dessa situação uma confirmação da qualidade emocional de sua vida em comum? Ninguém ensinou a ele as regras que se devem seguir para dar um presente e festejar um aniversário. E, no entanto, esse homem dispõe de um saber que diz respeito à importância da escolha de um presente e ao modo de oferecê-lo. De que maneira a mulher que recebe o presente sabe o que significa o presente assim escolhido e a festa assim organizada, e de que maneira conhece o modo como deve reagir para que esse café da manhã torne-se a celebração de uma vida em comum? As regras também não foram ensinadas a ela. E, no entanto, ambos sabem o que está em jogo, o que têm a fazer, como se devem comportar em relação ao outro, a fim de que essa manhã torne-se a celebração de sua vida em comum.

Para que esse processo ritual possa dar certo, vários elementos devem estar reunidos. Em primeiro lugar, um saber comum relativo ao pano de fundo cultural e social: o que significa um aniversário em uma harmoniosa relação a dois; de que modo ele é celebrado; quais são os deveres da pessoa cujo aniversário é festejado e os de seu(sua) parceiro(a). Em segundo lugar, uma intencionalidade compartilhada, que leva as duas pessoas a agirem, referindo-se à outra de modo complementar. Por fim, a festa de aniversário só será bem-sucedida se as duas pessoas cooperarem. $\mathrm{O}$ sucesso decorre de sua cooperação mútua e conduz ao fortalecimento da relação. Mas isso só acontecerá se houver uma atenção recíproca, alimentada pelo cuidado com o outro e pela ternura que a ele se dedica. Tais emoções conferem à ação dessas duas pessoas seu significado social.

Esses processos são viabilizados pela relação mimética mútua e pluridimensional entre a mulher que faz aniversário e o marido que deseja festejá-lo. Essa relação complementar é a condição prévia do sucesso da festa. Ela cria, por meio de repetições ritualizadas, mesmo em contextos diferentes, o saber prático necessário ao bom êxito da ação.

Tais situações só serão bem-sucedidas se todas as partes envolvidas tiverem um conhecimento prático e performativo daquilo que devem fazer, da maneira como devem reagir e se colocar em cena em relação ao outro (Wulf, 2005, 2006; Wulf; Göhlich; Zirfas, 2001; Wulf; Zirfas, 2007). Seu agir provém de um saber prático relativo à maneira e ao momento em que eles "representam" essa ou aquela situação; por uma encenação que lhes é própria, eles sabem como responder às expectativas do outro, ou contradizê-las. Aprenderam isso nas inúmeras ocasiões da vida cotidiana, vendo seus pais prepararem os próprios aniversários e os de seus irmãos e irmãs. Nessas situações, certamente não havia velas flutuando entre folhas de hera, nem uma reflexão que levava à compra de um anel de rubi-califórnia. Mas houve outros exemplos de encenações da procura de um presente capaz de dar prazer ao presenteado; de solicitude afetuosa pelo(a) aniversariante; da felicidade de uma vida em comum. Aconteceram outros aniversários nos quais, por exemplo, os irmãos e as irmãs manifestaram sua afeição por meio de comentários agressivos e maliciosos, em que se cantavam canções, em que os presentes correspondiam a desejos claramente 
expressos. Apesar dessas diferenças, os aniversários assemelham-se uns aos outros sob diversos aspectos. Nos processos miméticos, formam-se, nas partes envolvidas, imagens interiores e sequências performativas que servem de material para organizar, em situações análogas, a expressão e a representação da oferenda, da recepção do presente, da festa dada e recebida.

Sempre que agimos em relação a uma prática social existente, produzindo também, desse modo, uma nova prática social, instaura-se entre as duas ações uma relação de mimetismo; quando, como no exemplo do presente citado anteriormente, entregamo-nos a uma prática social, agimos de acordo com um modelo social e expressamos por meio do corpo uma representação social. Mas não se trata, nesse caso - como vimos -, unicamente de imitação. As ações miméticas não são meras reproduções que obedecem cegamente a um determinado modelo. Nas práticas sociais realizadas por mimetismo acontece algo inteiramente particular.

Diferentemente dos processos de mimicry, nos quais ocorre apenas uma adaptação a determinadas condições, os processos miméticos - como ilustra o exemplo do presente - induzem ao mesmo tempo semelhanças e diferenças em relação às situações e às pessoas às quais eles se referem. Por assimilação gradual, em virtude de situações já conhecidas ou dos universos culturais que os marcaram, os sujeitos adquirem a capacidade de se orientar no campo do social. Ao participar das práticas sociais do outro, eles ampliam seu mundo vivido (Lebenswelt) e desenvolvem novas capacidades de experiência e de ação. Receptividade e atividade entrelaçam-se. Nesse processo, o mundo dado cruza-se com a individualidade daqueles que se referem a ele por mimetismo. Os seres humanos recriam as situações que já conhecem por experiência própria ou o universo que existe fora deles mesmos. Por meio dessa reduplicação, apropriam-se desse universo e adquirem sua individualidade própria em relação a uma situação anterior ou a um mundo exterior. Ao longo desse processo, o excedente de energia, que é indeterminado no ser humano, assume a forma de desejos e de necessidades individuais. $\mathrm{O}$ confronto entre o exterior e a formação do eu aparece no mesmo sistema. Os mundos exteriores e interiores aproximam-se continuamente uns dos outros e só podem ser apreendidos nessa correlação. Entre o interior e o exterior surgem semelhanças e correspondências. Os seres humanos assemelham-se ao mundo e ao mesmo tempo modificam-se. Ao longo dessa transformação, sua percepção do exterior se altera, assim como se altera a percepção que têm de si mesmos.

Os processos miméticos ocasionam, por meio da sensação, a descoberta de semelhanças e permitem estabelecer correspondências com o ambiente social. Por meio dessa experiência, o homem coloca-se à prova do sentido. Reconhecer as semelhanças faz parte das aptidões precoces da espécie humana. Essas semelhanças existem em fenômenos que são correlatos entre si do ponto de vista dos sentidos. Pode acontecer entre dois rostos, ou manifestar-se por ocasião de processos em que um homem imita o que algum outro faz. Entre o animado e o inanimado, podem ser descobertas formas de semelhança. $\mathrm{O}$ corpo humano serve para produzir e expressar as semelhanças. A dança e a linguagem são exemplos patentes disso. A representação e a expressão, a encenação e o comportamento não diferem nem 
na dança nem na linguagem. Trata-se aí de aspectos que não estão dissociados na mimese, mas que se entrecruzam no interior de um ato.

Nos processos miméticos, a aquisição de um saber prático não se baseia necessariamente nas semelhanças. Quando o saber mimético é adquirido por meio da referência a um agir social anterior ou a representações performativas, somente uma comparação entre os dois mundos permitirá estabelecer o ponto de vista preciso da referência mimética. A semelhança, é bem verdade, desencadeia quase sempre o impulso mimético. No entanto, até mesmo a criação de um contato mágico pode tornar-se o ponto de partida de uma ação mimética. Uma referência mimética é necessária, mesmo nos casos em que o importante é diferenciar-se de práticas sociais existentes. Aceitar o agir social anterior, modificá-lo ou rejeitá-lo integralmente são atitudes que passam pela referência mimética.

Nos processos de aprendizagem mimética, é feita novamente a experiência de uma ação social anterior. A referência não provém de um pensamento teórico, ela é produzida esteticamente, por meio dos sentidos. Se compararmos as duas ações, a segunda difere da primeira na medida em que não se confronta com ela diretamente; não a modifica, mas a reitera. A ação mimética tem um caráter a um só tempo demonstrativo e representativo; sua representação cênica faz aparecerem qualidades estéticas próprias. Os processos miméticos fazem referência a mundos sociais de que o indivíduo já fez a experiência, e que não são nem efetivamente existentes, nem imaginários.

O caráter dinâmico de uma ação social está associado ao fato de que o saber necessário à sua encenação é de natureza prática. Como tal, ele está menos submetido ao controle racional do que o saber analítico. Com efeito, o saber prático ritual não é um saber reflexivo nem consciente de si mesmo. Ele só adquire essas características em um contexto de conflito e de crise em que os atos gerados por ele demandam uma explicação racional. Quando a prática social não é questionada, o saber prático permanece, por assim dizer, semiconsciente. Assim como o saber do habitus, o saber prático compreende imagens, esquemas e formas de ação que são convocadas pela encenação dos corpos na teatralização dos atos sociais. Ninguém se pergunta se eles convêm; eles são simplesmente conhecidos e citados na encenação da prática social.

A dotação instintiva residual, o hiato entre estímulo e reação, e "a excentricidade" são as condições da plasticidade excepcional do ser humano. Citemos ainda as capacidades no que se refere à aquisição de um saber prático, que permitem ao homem planejar, encenar e representar o agir social. Os movimentos corporais que tornam possível a ordenação das cenas do agir social são parte integrante desse saber prático. Em consequência da "disciplinarização" e do controle dos movimentos corporais, nasce um saber prático disciplinado e controlado, o qual, conservado na memória do corpo, permite a encenação das formas correspondentes de um agir simbólico e cênico. Esse saber prático refere-se a formas de agir e de teatralização sociais que têm sua origem na cultura. Trata-se, portanto, de um saber fortemente marcado, porém limitado em suas possibilidades históricas e culturais.

Nos processos miméticos, ocorre uma alteração imitativa dos mundos anteriores, bem como uma nova ordenação deles. É esse o fator de inovação característico dos atos miméticos. As práticas sociais são miméticas sempre que se referem 
a outros atos e podem, elas mesmas, ser concebidas como ordenações sociais; elas podem ser independentes ou fazer referência a outras ações. As ações sociais são possibilitadas pelo desenvolvimento de um saber prático que intervém no decorrer de processos miméticos. O saber prático pertinente para as ações sociais é, a um só tempo, corporal e lúdico, histórico e cultural. Ele é construído em situações de "face a face"; não é unívoco do ponto de vista semântico; inclui componentes imaginários e não pode ser reduzido à intencionalidade. Por fim, ele comporta um excedente de significado e manifesta-se na encenação e na teatralização social da religião, da política e da vida cotidiana.

\section{REFERÊNCIAS}

Aristotle. Poetics. Chapel Hill: University of Northe Carolina Press, 1958.

Benjamin, W. Berlin childhood around 1900. Cambridge, MA: Belknap Press of Harvard University Press, 2006.

Else, G. F. Imitation in the 5th century. Classical Philology, Chicago: University of Chicago Press, v. 53, n. 2, p. 73-90, 1958.

Gebauer, G.; Wulf, C. Mimesis. Culture, art, society. Berkeley: University of California Press, 1995.

;_ Mimese na cultura. Agir social, rituais e jogos, produções estéticas. São Paulo: Annablume, 2004a.

; _ Jeux, rituels, gestes. Les fondements mimétiques de l'action sociale. Paris: Anthropos, 2004b.

Girard, R. Violence and the sacred. Baltimore,MD: Johns Hopkins University Press, 1977. . The scapegoat. Baltimore, MD: Johns Hopkins University Press, 1986.

Huppauf, B.; Wulf, C. Dynamics and performativity of imagination. The image between the visible and the invisible. New York: Routledge, 2009.

Koller, H. Die Mimesis in der Antike: Nachahmung, Darstellung, Ausdruck. Bern: Francke, 1954.

Plato. The Republic. New York: Basic Books, 1968.

Ricoeur, P. Time and narrative. Chicago: University of Chicago Press, 1984-1988. 3v. Soerbom, G. Mimesis and art: studies in the origin and early development of an aesthetic vocabulary. Uppsala: Appelbohm, 1966.

Tomasello, M. The cultural origins of human cognition. Cambridge, MA: Harvard University Press, 1999.

. Origins of human communication. Cambridge, MA; London: MIT Press, 2008.

Wulf, C. Anthropologie de l'education. Paris: L'Harmattan, 1999 (Spanish editon: Anthropología de la educación. Barcelona: Idea Books, 2004).

Traité d'anthropologie historique. Philosophies, histoires, cultures. Paris: L'Harmattan, 2002. 
Rituels. Performativité et dynamique des pratiques sociales. Hermès, "Rituels", Paris: CNRS, v. 43, p. 9-20, 2005.

Praxis. In: Kreinath, J.; Snoek, J.; Strausberg, M. (Eds.). Theorizing rituals: issues, topics, approaches, concepts. Leiden: Bill, 2006.

Une anthropologie historique et culturelle. Rituels, mimésis sociale, performativité. Paris: Tétraèdre, 2007.

Anthropology. A continental perspective. Chicago: Chicago University Press, 2013. (Spanish editon: Anthropología. Historia, cultura, filosofía. Barcelona, México: Anthropos, 2008). [Edição brasileira pela Annablume, São Paulo, 2012-2013]. 2004a.

. et al. Les pratiques sociales comme rituels. Une ethnographie. Paris: L'Harmattan,

.et al. Bildung im Ritual. Schule, Familie, Jugend, Medien. Wiesbaden: Verlag Sozialwissenschaften, 2004b.

.et al. Lernkulturen im Umbruch. Rituelle Praktiken in Schule, Medien, Familie und Jugend. Wiesbaden: Verlag Sozialwissenschaften, 2007.

. et al. Rituals and identity. The staging and performing of rituals in the lives of young people. London: Tufnell Press, 2010.

. et al. Gesten in Erziehung, Bildung und Sozialisation. Familie, Schule Jugendkultur, Medien. Wiesbaden: Verlag Sozialwissenschaften, 2011.

.; GöHlich, M.;Zirfas,J.(Hg.). Grundlagen des Performativen. Eine Einführung in die Zusammenhänge von Sprache, Macht und Handeln. Weinheim, München: Juventa, 2001.

.; Zirfas, J. (Hg.). Die Pädagogik des Performativen. Theorien, Methoden, Perspektiven. Weinheim, Basel: Beltz, 2007.

Zuckerkandu, V. Mimesis. Merkur: Stuttgart: Klett-Cotta, n. 12, v. 121, p. 225-240, 1958.

\section{SOBRE O AUTOR}

Christoph Wulf é doutor em filosofia pela Philipp University of Marburg (Alemanha). Professor da Freie Universität Berlin (Alemanha). E-mail: christoph.wulf@fu-berlin.de

Recebido em novembro de 2014 Aprovado em maio de 2015 